\title{
Editorial
}

\section{Denise Robinson}

\section{University of Huddersfield}

HUDCETT

As we approach the end of the Centres for Excellence in Teacher Training (CETTs') initial period of support from the Learning and Skills Improvement Service (LSIS) we can look at the outputs and improvements that have come about with pride. In what has been a mere 30 months (since their operational launch in September 2007), the CETTs have made considerable contributions to the resources, networking and procedures and processes around Initial Teacher Training (ITT) and Continuing Professional Development (CPD). This Journal is evidence of one of those resources that help to inform and stimulate debate in the sector.

This edition continues the theme of contributing to the discourses around the major issues that confront ITT and all teachers across the sector. Of the six papers, four of them are focused on the issues that are close to the hearts of all teacher educators; subject specialist mentors; trainee teachers and their perceptions of their training and development needs; the professionalisation agenda; and the confusion that still prevails over the Certificate in Teaching in the Lifelong learning Sector (CTLLS) and the Associate teacher role; and a new expectation that we now include sustainable education as an integral element in the curriculum. A paper on Teacher Educators is to be welcomed; relatively little has been written about Teacher Educators in the sector but there is growing evidence of work being undertaken. The final paper probably affects all education sectors but is addressed to the FE sector. It addresses the question: what conditions do we need to establish for the long term benefit of our institutions, ourselves, our learners and society? The issues of trust as a basis for collaborative working are considered; there is a message for all of us in this.

We also report on three projects that are underway: ethical guidelines for research in FE; CPD for tutors on progression for level 3 vocational learners; and teacher educators' initiatives in the West Midlands. Again we have a good distribution from across the regions. We encourage more papers to be submitted for publication in future editions and we look forward to receiving these, whether they are papers or project/activity reports.

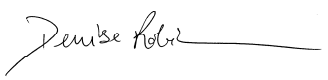

